\title{
Esophageal Obstruction due to Dried Shredded Squid
}

\author{
Yusaku Kajihara* \\ Department of Gastroenterology, Fuyoukai Murakami Hospital, Aomori, Japan
}

An 83-year-old woman presented to the author's department with a 3-day history of vomiting after the ingestion of solid foods. Computed tomography showed dilatation of the lower esophagus and esophageal food bolus (Fig. 1). Emergency endoscopy revealed a large indigestible mass in the lower esophagus (Fig. 2A). Since endoscopic fragmentation was impossible, overtube-assisted removal was performed. Further observation after the endoscopic removal confirmed wet entangled strings-like objects (Fig. 2B). Later, it was found that the objects consisted of dried shredded squid (Fig. 2C).

Although esophageal food bolus obstructions have been well reported in literature, this is the first case report of an esophageal obstruction caused by dried shredded squid. Esophageal food impaction may occur due to stricture, carcinoma, eosinophilic esophagitis, or achalasia. ${ }^{1}$ In addition, the risk factors for esophageal impaction include psychiatric disorders, developmental delay, alcohol intoxication, edentulous elderly patients, and prisoners seeking secondary gain. ${ }^{2,3}$ However, the patient was found to have none of the abovementioned conditions. Detailed inquiry revealed that the patient had often eaten dried shredded

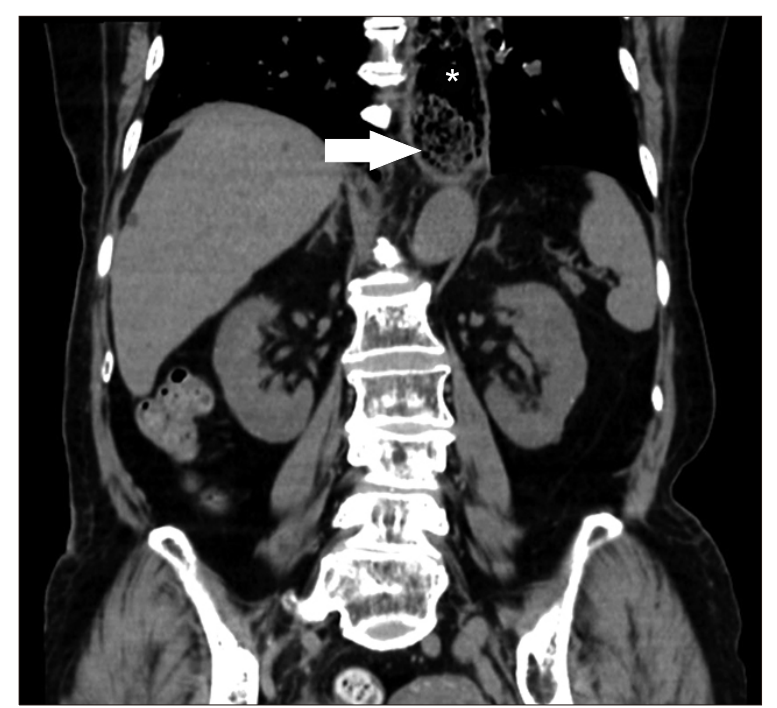

FiG. 1. Computed tomography showed dilatation of the lower esophagus (white asterisk) and esophageal food bolus (white arrow).
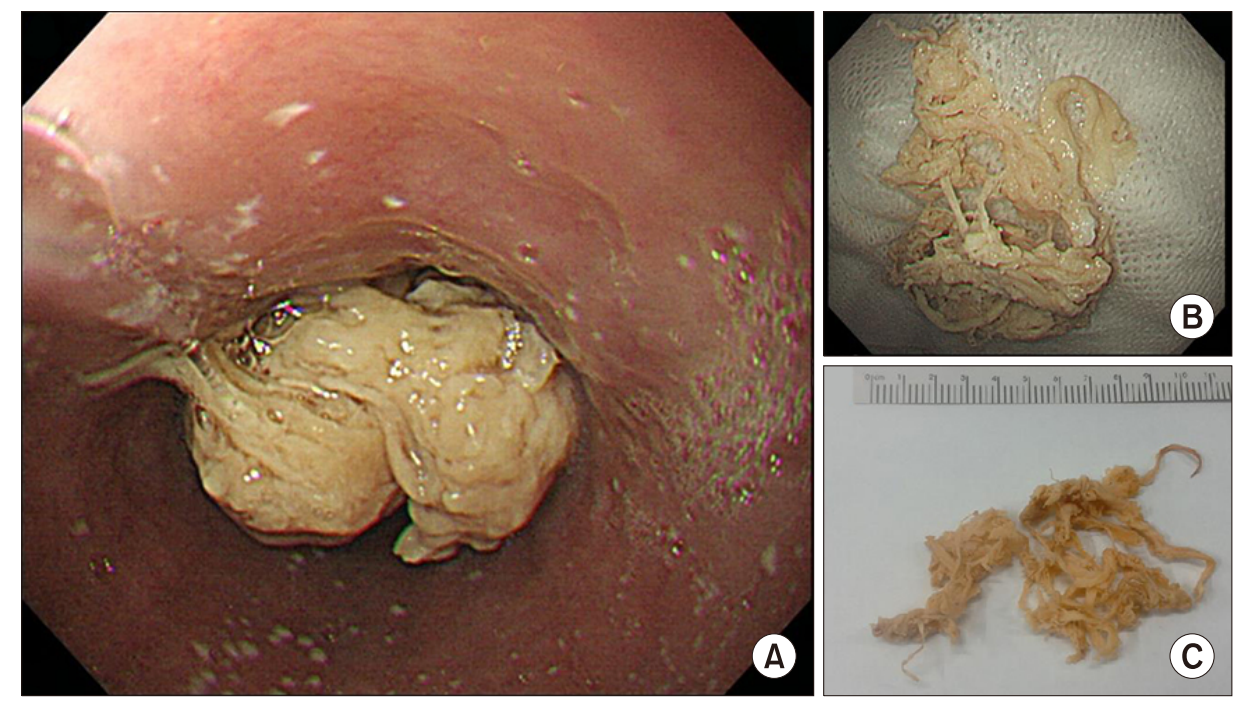

Corresponding Author:

Yusaku Kajihara

Department of Gastroenterology, Fuyoukai Murakami Hospital, 3-3-14 Hamada, Aomori 030-0843, Japan Tel: +81-17-729-8888, Fax: +81-17-729-8887, E-mail: yukajihara-gi@umin.ac.jp
FiG. 2. (A) Emergency endoscopy revealed a large indigestible mass in the lower esophagus. (B) Further observation after the endoscopic removal confirmed wet entangled strings-like objects. (C) Later, it was found that the objects consisted of dried shredded squid.

\section{Article History:}

Received November 10, 2019 Revised November 28, 2019 Accepted December 1, 2019 
squid as a midnight snack. Dried shredded squid is a popular snack in coastal East Asia, including, Korea, Japan, and China. It was found that for prevention of conditions like this, it is important to chew thoroughly before drinking an adequate amount of water and avoid lying down immediately after eating.

\section{CONFLICT OF INTEREST STATEMENT}

None declared.

\section{REFERENCES}

1. Fung BM, Sweetser S, Wong Kee Song LM, Tabibian JH. Foreign object ingestion and esophageal food impaction: an update and review on endoscopic management. World J Gastrointest Endosc 2019;11:174-92.

2. ASGE Standards of Practice Committee, Ikenberry SO, Jue TL, Anderson MA, Appalaneni V, Banerjee S, et al. Management of ingested foreign bodies and food impactions. Gastrointest Endosc 2011;73:1085-91.

3. Khayyat YM. Pharmacological management of esophageal food bolus impaction. Emerg Med Int 2013;2013:924015.

This is an Open Access article distributed under the terms of the Creative Commons Attribution Non-Commercial License (http://creativecommons.org/licenses/ by-nc/4.0) which permits unrestricted non-commercial use, distribution, and reproduction in any medium, provided the original work is properly cited. 